\title{
Use of Blackboard Collaborate at Qassim University: Evaluating Teachers' Perceptions
}

\author{
Nisreen Juma'a Hamed Al-Mashaqba \\ College of Science and Arts, Methnab, Qassim University, Saudi Arabia
}

\begin{abstract}
Learning has come a long way from the conventional blackboard that marked the earlier decades to the new age Blackboard Collaborate which enables learners to work and learn in a collaborative online environment. Virtual classrooms, especially with learners sharing in academic workload on portals such as Google Docs, have arrived as a natural development of the ICT (In Circuit Tester) wave. In addition to offering ample scope for peer interaction, Blackboard Collaborate gives learners the electronic environment they are most familiar with and keeps them updated with the latest educational tools. However, for it to succeed, the perception of the teachers is a factor that needs close scrutiny before this tool can be incorporated into the system. The aim of this paper is to investigate the perceptions of teachers at Qassim University, KSA (Kingdom of Saudi Arabia) towards the inclusion of Blackboard Collaborate into the teaching-learning environment, and its efficacy as a learning tool in the university's EFL (English as a Foreign Language) situation.
\end{abstract}

Keywords: Blackboard Collaborate, collaborative learning, e-learning, blended learning, online learning, teachers' perception

\section{Introduction}

With the massive growth in computer technology for communication and preference for socialization through media such as emails, Twitter, and Facebook, the use of computers in real time has become deeply integrated with the lives of the youngsters. Consequently, the internet is today the most potent tool of learning available across divisions of race, nation, and gender. Modern classrooms extend beyond the physical limits of the school and run well into the learners' cafeteria, locker rooms and homes. Collaborative e-learning springs from here. Collaborative web-based learning hinges on the notion first propounded by Zimmerman (1989) and later reinforced by Pintrich (2000) that collaboration plays a vital role in learning since the latter is a socially mediated process. Collaborative learning drastically reduces the cognitive load on working memory enabling the group members to construct higher quality schemata in the long term memory leading to better learning of complex tasks (Kirschner, Pass \& Kirscher, 2009). With this grounding in favour of integrating technology into learning, this paper aims to study the perceptions of one of the two important elements in the teaching-learning situation: That of the teachers.

\section{Literature Review}

In a remarkable and landmark study on the effects of Blackboard Collaborate on ESL/EFL

Nisreen Juma'a Hamed Al-Mashaqba, assistant professor, Ph.D., College of Science and Arts, Methnab, Qassim University. 
teachers-learners (Hussein, 2016), the subjects were students at a teacher training institute. It is significant for the current study that Hussein investigated the students' achievement in teaching methods course as a result of Blackboard Collaborate intervention. The differences found in the pre- and post-test mean scores of the experimental group in the EFL teaching methods test are a significant 0.05 .

HUANG, YANG, CHIANG and SU (2016) conducted a study wherein they tested and compared the outcomes of the use of a FSLV (5-step vocabulary learning) strategy and the mobile tools with FSLV strategy and traditional learning tools on situational English vocabulary learning environment. The results showed that applying the functions of mobile learning tool with respect to vocabulary such as automatic search of new words and their meaning, worked in two beneficial ways for the students: (1) They understood the meaning of the new words and (2) remembered new words without referring to the dictionary. Further, this vocabulary building was regardless of whether the group was performing designated learning activities. This is a significant finding because understanding new words and retrieving them from memory along with the related schema is an important step in foreign language acquisition. The same study also opened doors to the low-learning-ability students who could quickly see when their performance lagged behind the others and hence, endeavoured to seek the assistance of the high-learning-ability students because of the co-operative nature of the activity.

Mazzoni and Benvenuti (2015) carried out a unique study to analyze the effectiveness of a humanoid robot in improving young children's knowledge of English words in an ESL environment. The results drew a comparison between the performance of child-child pair to child-robot pair in language output. They concluded that the presence of the robot did not prove more effective than a human counterpart. However, what is significant is their recommendation to analyze the outcomes by replacing the robot with smart phones and tablets.

Ford and Rice (2015) carried out a study to determine the difference, if any, in the value added results in standardized tests in English and Mathematics between virtual schools and traditional schools in California. It may be pointed out here that they quote Staker (2011) early in the study stating that the number of K-12 online schools shot up to four million in 2010 from approximately 45,000 in year 2000. Clearly, online education is being opted for by large numbers especially in the West.

In another remarkable study, Miron and David (2015) conducted a case study on the use of Facebook Groups as an academic teaching aid. They quote Fordham and Goddard (2013) who list the following uses of Facebook as a teaching aid in academic courses as part of Formal Learning:

(1) As a support to the teaching of any curricular subject;

(2) A space and platform for homework and revision resources;

(3) A portal to run debates;

(4) Peer tutoring and support;

(5) A research tool to post and share ideas, videos, and resources.

Similarly, Zaki and El Zawaidy (2014) conducted a study of business writing programmes and discovered that learners in the traditional classroom setting interrelated with each other in a lesser manner than learners in a distant learning Blackboard class.

The provision of distance learning (also referred to as online learning or e-learning) curriculums has become accepted as one of the alternate delivery approaches for education and teaching in all parts of the world 
(Zaki \& El Zawaidy, 2014). Its virtue lies in the emphasis on a learner's procurement (or generation) of innovative knowledge.

Similar to knowledge management, distance learning includes the application of electronic devices (the Internet, televisions, storage devices, mobile phones, etc.) for education and learning from a remote location (Britain \& Liber, 2012).

According to Uzunboylu and Ozdaml (2011), knowledge management and distance learning are similar as they provide solutions to the same essential challenge, which is to assist and simplify learning in educational institutions.

Needless to say, distance learning has revolutionised the notion of education and transformed it from the traditional classroom-based teaching to online-based programmes, comprising of various education resources, which are linked to each other in a significant way.

However, a pedagogy that is popular in the developing world is Blended Learning. It captures the best of both worlds by allowing learners to pick and choose how they want to learn and affords them greater flexibility and convenience about when they want to learn. It can be as simple as combining two different learning methods (reading a book before going to a classroom) or as complex as obtaining a degree via a longer-term distance education program. It is a formal education program in which a student learns at least in part through delivery of content and instruction via digital and online media with some elements of student control over time, place, path, or pace. While still attending a "brick-and-mortar" school structure, face-to-face classroom methods are combined with computer-mediated activities.

To keep pace with the dynamic needs of the learners, the definition of blended learning has changed from a simple blend of classroom training and e-learning courses to more complex programs that incorporate an array of synchronous and asynchronous learning modalities. Apart from aiding formal education, Blended Learning can support a variety of informal learning processes, such as training individuals on-job.

Finally, it is necessary to talk of Blackboard Collaborate. This is a browser-based web conferencing service that makes synchronous collaboration simple and crystal clear. It employs Java-less launching and easy deployment which means that one can focus on teaching and learning, not technology skills. Blackboard Collaborate is characterized by ease of use and rapidity of deployment, making possible powerful information sharing and straightforward collaboration (Boulos, Maramba \& Wheeler, 2006). Further, it affords the added advantage of reducing the technical skill required to use its features, allowing users to focus on the information exchange and collaborative tasks themselves without the distraction of a difficult technological environment (Kirkpatrick, 2006). Such "transparent technologies" (Wheeler, Kelly \& Gale, 2005) let the user concentrate more on the learning task by "seeing through" the technology with which they are interacting. Schaffert, Bischof, Burger and Schon (2006) have rightly stated that social software helps to realize the original vision of the Web as a space in which anyone can participate.

Blackboard Collaborate has the potential to complement, enhance, and add new collaborative dimensions to the classroom. Social software offers a variety of unique and powerful information sharing and collaboration features, acting as cognitive reflection and amplification tools and aiding the construction of meaning through the act of self-design of knowledge databases (Jonassen, Peck \& Wilson, 1999).

\section{What Is Blackboard Collaborate}

Blackboard Collaborate is a system that allows participants to collaborate online in real time. It has been 
designed with educational uses in mind and has a multitude of features including:

(1) Audio-conferencing;

(2) Video-conferencing (allowing up to six simultaneous web-cams to be viewed);

(3) Real-time polling and quizzes (including multiple choice questions);

(4) Application sharing (allowing applications on one computer to be seen by all participants);

(5) Text chatting (instant messaging);

(6) Playing of audio and video files;

(7) File transfer;

(8) Whiteboard (a shared space that everyone can see, allowing attendees to, e.g., draw/write on and import graphics, photos, and PowerPoint files);

(9) Shared web browsing - called "web tour" (allowing attendees to follow one person as they browse the web);

(10) Break-out rooms (for small-group discussions and collaboration);

(11) Recording of sessions (allowing playback at a later time) and capturing of content generated in a session, e.g., text-chat and whiteboard.

In addition, Blackboard Collaborate incorporates management functions to support those running a Blackboard Collaborate session.

\section{Why Blackboard Collaborate}

There are a range of benefits from using Blackboard Collaborate:

(1) It can help build learner peer collaboration and a sense of community, particularly with distance learning/work-based learners;

(2) It can be used to support a wide range of teaching/learning methods and styles, potentially in highly engaging and collaborative forms with seamless integration with each attendee's desktop computing;

(3) Recording of sessions allows learners to access them anytime, e.g., to help re-enforce the learning and all participants can save the Whiteboard, text-chats, screen images, etc.;

(4) It allows external participants to cost-effectively participate in sessions, e.g., external experts, external examiners, mentors, supervisors, assessors, and interviewees;

(5) It extends geographical reach to anyone with an Internet connection and computer;

(6) It provides greater flexibility to arrange sessions cost-effectively without participants having to travel as well as providing potential savings in travel costs;

(7) It can be used in a multitude of ways in addition to teaching, learning, and assessment, e.g., to support collaborative working (thereby potentially increasing staff efficiency), running of online conferences, socialising, staff professional development, and "web-casting" of workshops, seminars, and interviews;

(8) It can be combined and integrated with other e-learning methods, e.g., VLEs (Virtual Learning Environments), asynchronous discussions, and wikis;

(9) Blackboard Collaborate is a multi-platform device, e.g., PCs (personal computers), Apples, and Linux-based systems, therefore most participants are likely to be able to access it. Furthermore, it works even on low-bandwidth connections;

(10) Its use minimises the impact on the environment (minimising travel and printing); 
(11) The tool, Blackboard Collaborate, supports online synchronous collaboration;

(12) The Blackboard Collaborate platform enables lecturers to implement instructor-led synchronous and asynchronous online training into their teaching and learning methodologies;

(13) Blackboard Collaborate allows students or lecturers to launch a synchronous or an asynchronous session directly from Blackboard Learn (Blackboard).

\section{Comparing E-learning and Traditional Learning}

Valentina and Nelly (2014) found connections between the level of social interactions between learners and their learning outcomes. E-learning has remarkably changed the framework for teaching and learning and supporters of e-learning have contended that it could be efficient for possibly reducing obstacles while offering improved suitability, flexibility, and personalised learning, which traditional classroom learning does not provide (Raaij \& Scheepers, 2006; Aljawarneh, Muhsin, Faisal \& Alkateeb, 2012). On the other hand, the opponents of e-learning have expressed concern that it makes learners isolated and disorganised, while decreasing the level of students' interest in their curriculum.

According to Al-Hassan (2011), traditional learning can be referred to as the learning which occurs within the constraints of a classroom, with a tutor present, and which is fixed in nature. Furthermore, the researcher posits that traditional learning is often carried out with the entire classroom of students being participators and takes place on an educational institute's premises. The features of traditional learning are the writing board, notebooks, teacher and students within a classroom, while those of e-learning include content delivery in various layouts, organisation of knowledge, interconnected learners, and tutors.

The progress of these two methods of teaching within the modern educational world brings about various debates on the benefits of one method and the limitations of the other. In comparison to distance and online learning, various studies have concluded that e-learning is a more efficient teaching method than traditional learning (Raaij \& Scheepers, 2006; Aljawarneh, Muhsin, Faisal \& Alkateeb, 2012). Researchers, such as Raaij and Scheepers (2006), posit that distance and online learning has the benefit of having the power of the Internet to support all learning contents. The scholars add that e-learning offers fast-paced learning at a lower cost, facilitated access to educational curriculum, and responsibility for all contributors within the learning procedure.

On the other hand, there are other studies that have contended that distance learning results in a decrease in social relationship and collaboration and an increase in expenses and introduction of technological issues with regards to information and communications technologies (ICTs) (Oye, Iahad, NorZairahab \& Rahim, 2012). In the same vein as Oye et al. (2012), Uzunboylu and Ozdaml (2011) also contend that these advantages do not necessarily ensure improved educational activities, as e-learning results in no social collaboration between students and teachers, as technology takes the place of social communication.

Yet other studies have suggested that e-learning platforms such as Blackboard provide the opportunity for learners to discuss online and share knowledge, which positively affects students' education, in comparison to the more traditional setting of being physically present in their classrooms. Kramarski and Mizrachi's (2006) research on a set of seventh grade Mathematics students discovered that students who participated in online dialogue and knowledge sharing had better outcomes than their equivalents who were taught in a traditional classroom setting. 
Correspondingly, Rodriguez, Jorge, Ismara, Ortiz and Dvorsky (2006) discovered that learners on a biology programme for non-majors who were active participants on online learning sites like Blackboard mostly had better scores during their final exams.

Nevertheless, as posited by Zawacki-Richter, Brown and Delport (2009), both methods of learning have their benefits and limitations and schools have to ensure that there is a balance in all learning programmes so that students gain the best learning experience.

\section{Research Questions}

This study attempts to answer the following questions:

(1) What was the perceived complexity of Blackboard Collaborate as a tool for the teachers to reflect on the service-learning endeavour?

(2) What was the effect of using Blackboard Collaborate as a tool of teaching in designing or producing educational materials?

(3) Is the integration of Blackboard Collaborate as a learning tool for students unique in the broader context of its use at the University?

\section{Methodology}

A five-day workshop, from 10 to 14 October, was arranged by Blackboard Collaborate to train the teachers at Qassim University in the use of this tool for teaching and for preparation of relevant teaching materials. This was a preliminary step before policy changes could be implemented for incorporation of this or other e-learning tools into the University pedagogy on a long-term basis. Thirty-two participants (teachers) attended the workshop. Sixteen were males and 16 females. All the participants are at least Masters' Degree holders while the highest qualification is Ph.D. Both male and female participants teach similar courses at the Methnab College of Arts and Sciences. At the end of the workshop, they were asked to develop two lessons each employing either Blackboard Collaborate or any other Web tool, such as Google Cloud and administer the lessons in the same week. Of these lessons, one was to be a repetition of an item already taught while the other was to be based on a new section of the curriculum. This was to be followed up with a short test to gather information about learning outcomes. Before obtaining these, a 17 item questionnaire with a five-point response scale, where "1" represents "never" or "rarely" and "5" represents "always" or "very often", was administered to the teachers. The aim of this was to obtain data on their perceptions to the use of Blackboard Collaborate as a teaching tool and development of relevant study materials.

\section{Findings and Interpretation of Data}

Data gathered from the questionnaire were analysed using the "Item Analysis" method to get an in-depth understanding of the results obtained. Presented here (Table 1) is the questionnaire with calculation of the mean scores. 
Table 1

\section{Mean Scores to Questionnaire}

Teachers' Perceptions to the Use of Blackboard Collaborate

\begin{tabular}{lll}
\hline Q No. & Question & Mean score \\
\hline 1 & The Blackboard Collaborate was my first workshop in technology use in teaching & 4.2 \\
2 & I am comfortable in the use of common computer devices I may need to apply the Collaborate tool & 4.0 \\
3 & I can choose the right software for a language item I am teaching & 2.4 \\
4 & Use of technology in the classroom makes me nervous & 4.7 \\
5 & I believe the use of technology like Blackboard will increase my productivity as a teacher & 4.9 \\
6 & I can use the Blackboard to interact with my peers to improve my teaching output & 4.6 \\
7 & I can manage common technology problems while using the Blackboard in my class & 2.3 \\
8 & I feel the Blackboard Collaborate is useful in producing meaningful research with my colleagues & 4.8 \\
9 & After attending the Blackboard workshop I have gained ideas on the use of other real-time technology & 4.0 \\
10 & tools for my teaching & 4.8 \\
11 & I do not have sufficient time to prepare my lessons using the Blackboard Collaborate & 4.7 \\
12 & I a-learning may foster a research outlook among my learners & 4.5 \\
13 & I am certain that my learners are already well versed with tech tools to enable them to use these in my & 4.8 \\
14 & EFL class & I need more training and orientation in the use of Blackboard Collaborate and other e-learning tools \\
15 & I feel enriched after attending the Blackboard workshop & 4.7 \\
16 & As part of the workshop, I could comfortably produce usable, topic specific teaching materials for use in & 4.3 \\
17 & real classroom & 3.8
\end{tabular}

\section{Item Analyses}

In-service teacher training is an ongoing and continuous process at Methnab College and teacher's feedback has always been encouraging about these. However, the mean score of 4.2 to Q1 about the frequency of training programmes in technology goes to show that much needs to be done in this direction. This finding is corroborated by the mean score of responses to Q3 which is low at 2.4 which demonstrates that the teachers are not much aware of the available software apart from Blackboard which can be integrated into their teaching practices.

Mean response of 4.0 to Q2 about the teachers' comfort level with the use of simple computers and accessories shows that they are end users of technology though they may not be experts in extended use of these. Perhaps vigorous and continued training in this direction will prove efficacious for the teachers to make their classrooms more in tune with the times.

In a very interesting finding, we can discern a close relation between the responses to Q4, 10, 11, and 14 . The mean scores for these rest at 4.7, 4.8, 4.7, and 4.7 respectively. Such a closely related mean score when seen together shows that teachers are nervous with the idea of using technology in the classrooms and this inhibition may spring from a dearth of time for preparing tech compatible lessons, fear of negative feedback from the parents and a less than proficient ability with the use of Blackboard Collaborate or other e-learning tools.

However, being well versed with the inroads that technology has made into our lives with $24 \times 7$ connectivity using social networks like Whattsapp, Facebook, and Twitter, the high mean scores of 4.9 and 4.8 to Q5 and Q13 respectively show that the teachers are aware of the fantastic possibilities with greater inclusion of technology into their teaching. 
One significant contribution that Blackboard Collaborate can play in academic development is answered by teachers' responses to Q6 and Q8. On using the Blackboard Collaborate in improving teacher's output by interacting with peers (Q6) and in using this tool to produce meaningful research in collaboration with the colleagues $(\mathrm{Q} 8)$, the mean scores are very encouraging at 4.6 and 4.8. This is a positive outcome for increasing the use of technology at the University in aiding the academic growth of the teachers.

Q9 about developing lateral thinking among the teachers by applying more web-based pedagogies in the classroom elicited a positive mean value of 4.0. This demonstrates the teachers' awareness about other options of e-learning that can be adopted at the University. They also understand that web collaboration can be used by the learners also in developing a research outlook as can be seen from the mean response to Q13. This score rests at 4.8. Finally, response to Q15 sums up the teachers' positive outlook to implementing Blackboard Collaborate as they found the workshop an enriching experience.

Answers to Q16 shed much light on the comfort level of the teachers in producing relevant teaching materials so as to use Blackboard Collaborate as a teaching tool in the class. Though the mean score rests at 3.8, individual answers demonstrate the teachers' keen interest in updating their e-skills to produce effective and usable materials that can also incorporate Blackboard Collaborate. While 24 teachers confess seeking the help of their more tech savvy colleagues in course design, eight teachers reported resorting to various e-portals and sites that help teachers prepare e-lessons. This finding, however, also necessitates better training of teachers in the use of modern techniques and technologies for course design and material production.

It has long been a part of the regular teaching scheme in the Western universities to use Blackboard Collaborate for language teaching. However, at Methnab University, inspite of it being one of the most modern universities in the country, use of technology, leave alone Blackboard Collaborate, is as good as absent in the classrooms. This finding comes about from the low mean score to Q17: Whether teachers have been using e-tools in language teaching.

\section{Conclusion}

Teaching complemented with visual aids, interactive web portals, and out-of-class teaching sustains learner's interest in the course and creates new knowledge content apart from adding variety to the conventional classroom environment. Information visualization tools create clarity and stimulate lateral thinking skills among the learners. Online quizzes and activities that take the lecture out of the confines of brick-and-mortar classrooms motivate learners to apply, synthesise, and create knowledge. The world is just beginning to explore the possibilities of learning in higher education. Blackboard Collaborate is one such possibility. This study has firmly established that the teaching community at Methnab College is prepared to usher in this change. With this as the starting point, we can move on to other technologies in e-learning. However, we realise there have been limitations to the study. Other studies in varied environments can help arrive at generalisations.

\section{Limitations of the Study}

The generalization of the results of the study will be limited by the following factors:

(1) This study is limited to the faculty members of Qassim University in Almethneb faculty of art and science; 
(2) This study focuses on Blended learning based on Blackboard Collaborate. Therefore, the results may not apply to other contexts such as Wiki, Forms, Google cloud, or other Virtual classrooms.

\section{References}

Al-Hassan, A. (2011). A comparison of e-learning and traditional classroom teaching. Jordan: Petra University.

Aljawarneh, S., Muhsin, Z., Faisal, A. N., \& Alkhateeb, E. A. (2012). E-learning tools and technologies in education: A perspective. Retrieved from www.people.math.sfu.ca

Arkorful, Valentina, Abaidoo, Nelly, (2014). The role of e-learning, the advantages and disadvantages of its adoption in higher education. International Journal of Education and Research, 2(12), 397-410.

Blackboard Inc. (2011). About Bb/press release archive. Retrieved January 22, 2016 from http://www.blackboard.com/news-and-events/pressreleases/archive.aspx?releaseid=1527263

Blackboard Inc. (2013). Blackboard Collaborate Web Conferencing Version 12.6.

Blackboard learn TM. (2009). Blackboard Inc. New York: McGraw Hill.

Blackboard support. (2014). Retrieved 6, 2015 from http://blackboardsupport.calpoly.edu/content/about/whatis.html

Blackboard. (2015). Integrate Blackboard Collaborate with your LMS. Retrieved November 6, 2015 from $\mathrm{http} / /$ www.blackboard.com/online-collaborative-learning/learning-management-systemintegration.aspx

Blackboard. (2016). Better collaboration means more effective learning. Retrieved from http://www.blackboard.com/online-collaborative-learning

Boulos, M. N. K., Maramba, I., \& Wheeler, S. (2006). Wikis, blogs and podcasts: A new generation of webbased tools for virtual collaborative clinical practice and education. BMC Medical Education, 6(41), 49-63. Retrieved November 2006 from http://www.biomedcentral.com/content/pdf/1472-6920-6-41.pdf

Britain, S., \& Liber, O. (2004). A framework for the pedagogical evaluation of virtual learning environments. Retrieved from http://digitalcommons.bolton.ac.uk/iec_reports/2

Ford, R., \& Rice, K. (2015). Value-added results for public virtual schools in California. Educational Technology \& Society, 18(4), 412-423.

Fordham, I., \& Goddard, T. (2013). Facebook guide for educators [Blog]. Retrieved from The Education Foundation-the UK's education think tank at http://www.ednfoundation.org/2013/06/21/facebook-guide-for-educators

HUANG, Chester S. J., YANG, Stephen J. H., CHIANG, Tosti H. C., SU, Addison Y. S. (2016). Effects of situated mobile learning approach on learning motivation and performance of EFL students. Journal of Educational Technology and Society, $19(1), 263-276$.

Hussein, E. M. (2016). The effect of blackboard collaborate-based instruction on pre-service teachers' achievement in the EFL teaching methods course at faculties of education for girls. English Language Teaching, 9(3), 49-67.

Jonassen, D. H., Peck, K. L., \& Wilson, B. G. (1999). Learning with technology: A constructivist perspective. Columbus, OH: Prentice Hall.

Kirkpatrick, M. (2006). The flu Wiki: A serious application of new web tools. Retrieved November 2006 from http://marshallk.blogspot.com/2005/07/flu-wiki-serious-applicationof-new.html

Kramarski, B., \& Mizrachi, N. (2006). Online discussion and self-regulated learning: Effects of instructional methods on mathematical literacy. Journal of Educational Research, 99(4), 218-230.

Krischner, F., Paas, F., \& Kirschner, P. A. (2009). Individual and group-based language from complex cognitive tasks: Effects on retention and transfer efficiency. Computers in Human Behaviour, 25, 306-314.

Mazzoni, E., \& Benvenuti, M. (2015). A robot-partner for preschool children learning English using socio-cognitive conflict. Journal of Educational Technology and Society, 18(4), 474-485.

Miron, E., \& David, G. (2015). Facebook groups as an academic teaching aid: Case study and recommendations for educators. Educational Technology \& Society, 18 (4), 371-384.

Oye, N. D., Iahad, A., NorZairahab, N., \& Rahim, N. (2012). The impact of UTAUT model and ICT theoretical framework on university academic staff: Focus on Adamawa State University, Nigeria. International Journal of Computers \& Technology, 2(2), 102-111.

Pintrich, P. R. (2000). Educational psychology at the millenium: A look back and look forward. Educational Psychologist, 35(4), 221-226. 
Raaij, M. van, \& Schepers, J. J. L. (2006). The acceptance and use of a virtual learning environment in China science direct. Computers \& Education, 50, 838-852.

Rodriguez, Jorge, Ortiz, Ismara, \& Dvorsky. (2006). Introducing evolution using online activities in a nonmajor biology course. Journal of College Science Teaching, 35(6), 31-35.

Schaffert, S., Bischof, D., Burger, T., Gruber, A., \& Hilzensauer, W. (2006). Learning with semantic Wikis. Proceedings of the first workshop on semantic Wikis: From Wiki to semantics (SemWiki2006) (pp. 109-123). Budva: Montenegro. Retrieved September 20, 2007 from http://www.wastl.net/download/paper/Schaffert06_SemWikiLearning.pdf

Staker, H. (2011). The rise of K-12 blended learning: Profiles of emerging models. Retrieved from www.innosightinstitute.org

Uzunboylu, H., \& Ozdaml, F. (2011). Teacher perception for m-learning: Scale development and teachers' perceptions. Journal of Computer Assisted Learning, 27(6), 544-556.

Wheeler, S., Kelly, P., \& Gale, K. (2005). The influence of online problem-based learning on teachers' professional practice and identity. ALT-J, 13(2), 125-137.

Zaki, H. A., \& El Zawaidy, H. (2014). Using blackboard in online learning at Saudi universities: Faculty member's perceptions and existing obstacles. International Interdisciplinary Journal of Education, 3(7), 141-150.

Zawacki-Richter, O., Brown, T., \& Delport, R. (2009). Mobile learning: From single project status into the mainstream? European Journal of Open, Distance and E-Learning. The International Review of Research in Open and Distributed Learning, 10(4), 415-435.

Zimmerman, B. J. (1989). A social cognitive view of self-regulated academic learning. Journal of Educational Psychology, 8(3), 329-339. 